\title{
Exploiting substrate cues for co-culturing cells in a micropattern
}

Akshay Joshi ${ }^{1}$, Tejinder Kaur ${ }^{1}$, Neetu Singh ${ }^{1,2 *}$

${ }^{1}$ Centre for Biomedical Engineering, Indian Institute of Technology Delhi, Hauz Khas, New

Delhi 110016, India

${ }^{2}$ Biomedical Engineering Unit, All India Institute of Medical Sciences, Ansari Nagar, New

Delhi 110029, India

*Corresponding author: Neetu Singh, Email: sneetu@iitd.ac.in 


\section{Supplementary Figures}

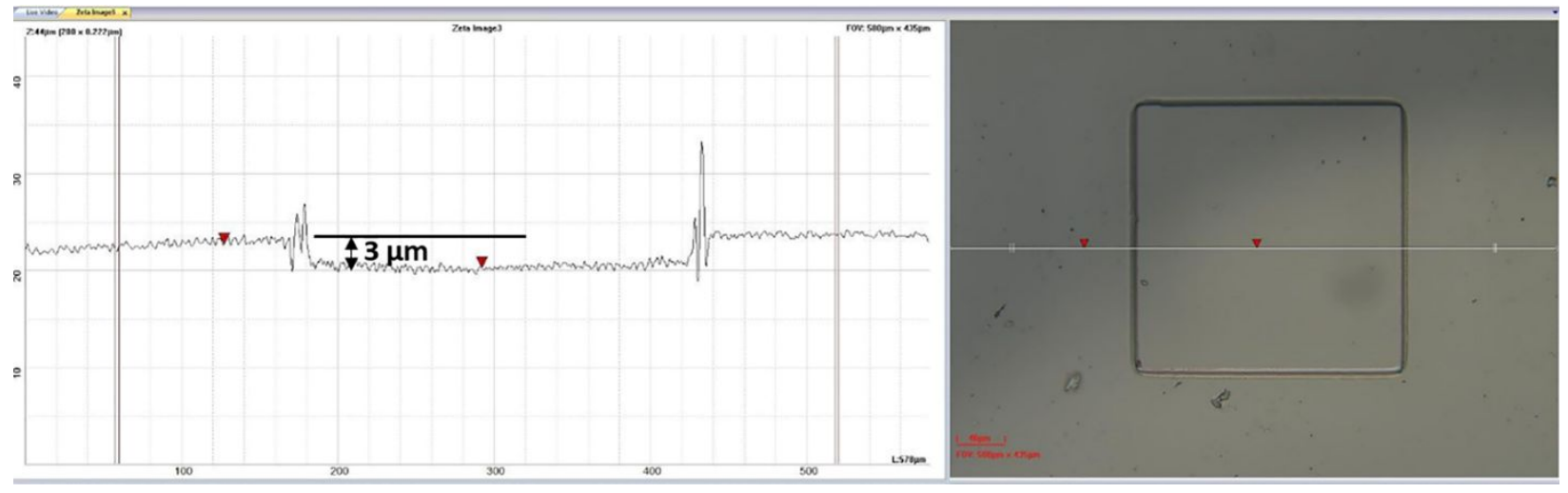

Figure S1. Optical profilometer data showing the depth of the patterns is around $3 \mu \mathrm{m}$ 
(a)
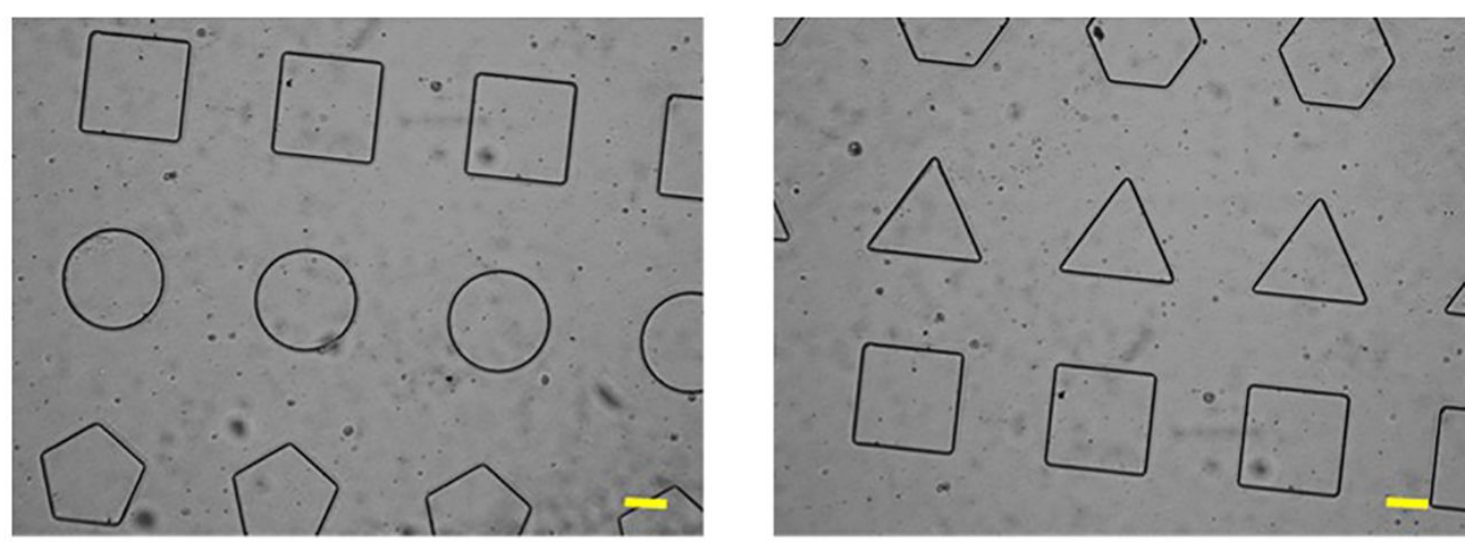

(b)
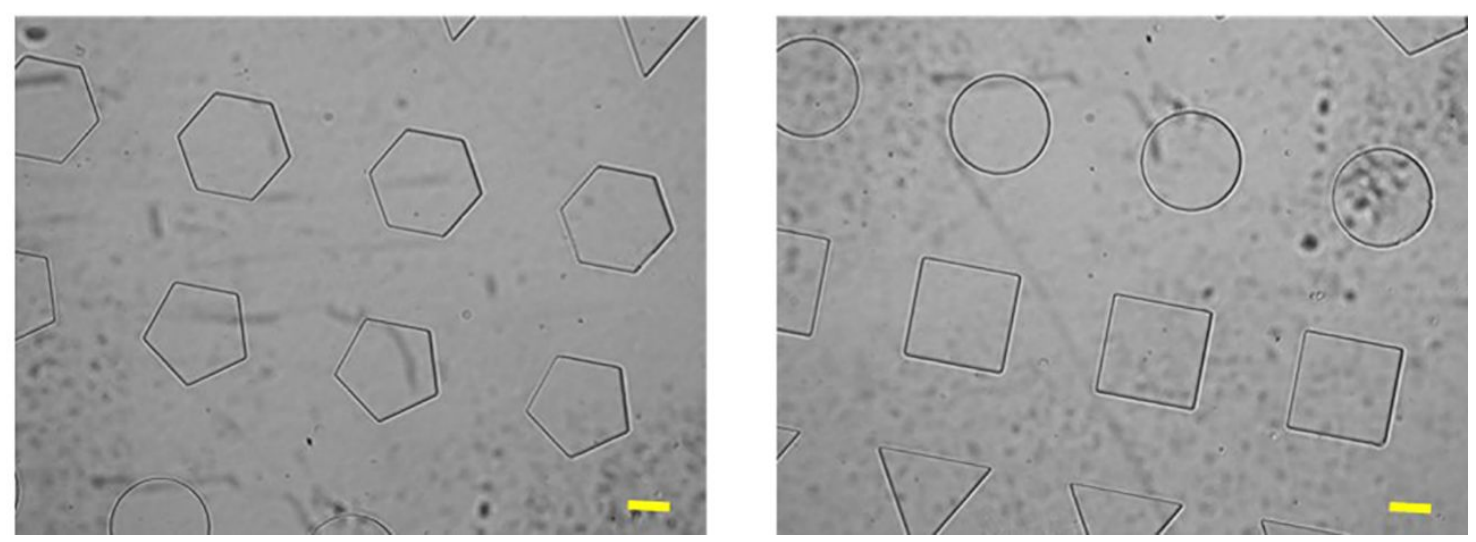

Figure S2. Bright field micrographs of $250 \mu \mathrm{m}$ sized patterns (a) At $0 \mathrm{~h}$ (b) After 5 days in PBS. The figure clearly shows that the pattern fidelity was maintained even after 5 days. (Scale $=200 \mu \mathrm{m}$ ) 

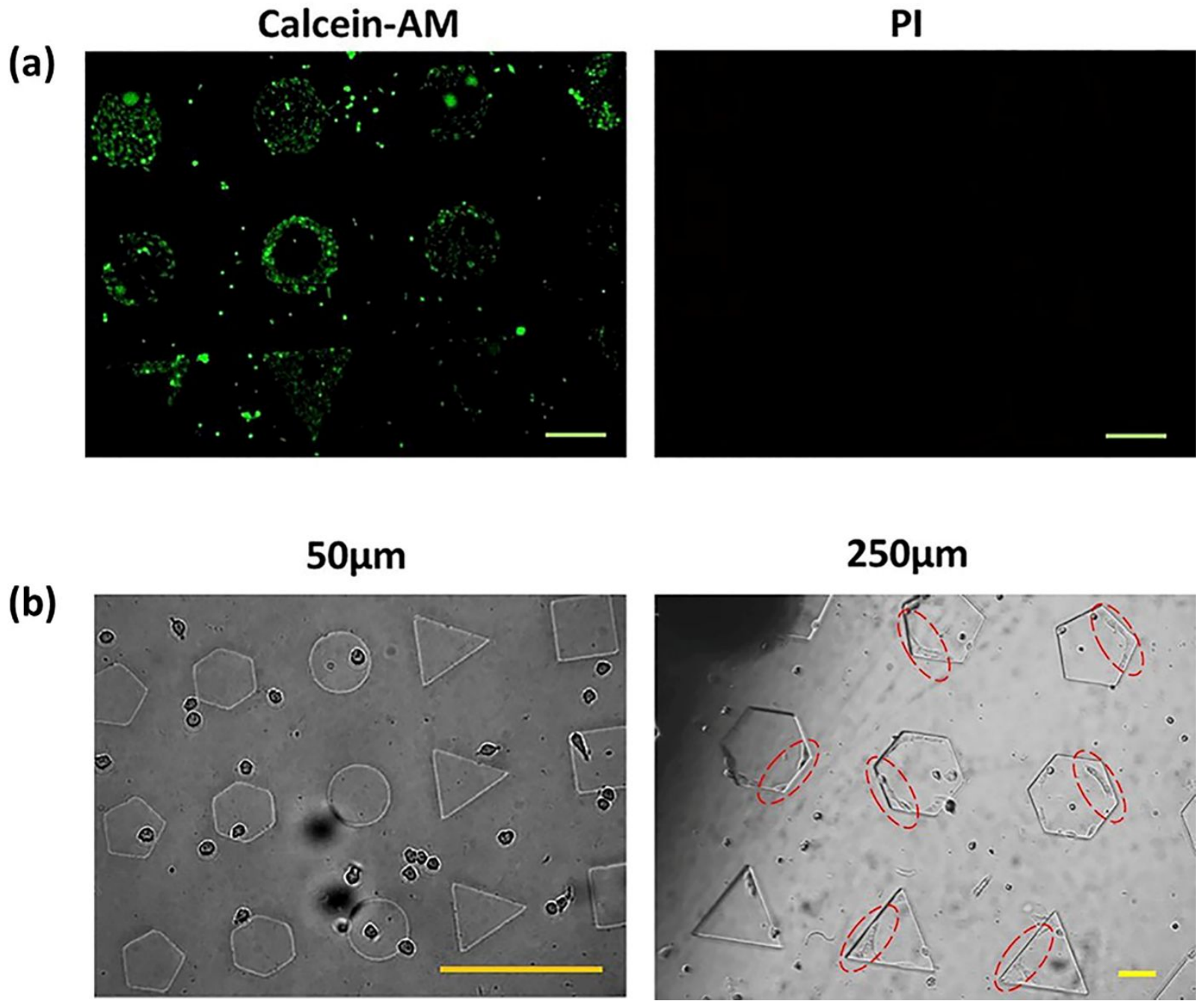

Figure S3. (a) Live and dead assay performed on patterned cells after $48 \mathrm{~h}$ of incubation (scale $=200 \mu \mathrm{m}$ ), (b) bright field images showing size dependent alignment of cells on patterns after $24 \mathrm{~h}$ of growth. The cells did not align in $50 \mu \mathrm{m}$ sized patterns even after $24 \mathrm{~h}$ of seeding. (Scale $=100 \mu \mathrm{m}$ ) (Marked area showing aligned cells in $250 \mu \mathrm{m}$ patterns after $24 \mathrm{~h}$ of cell seeding). 

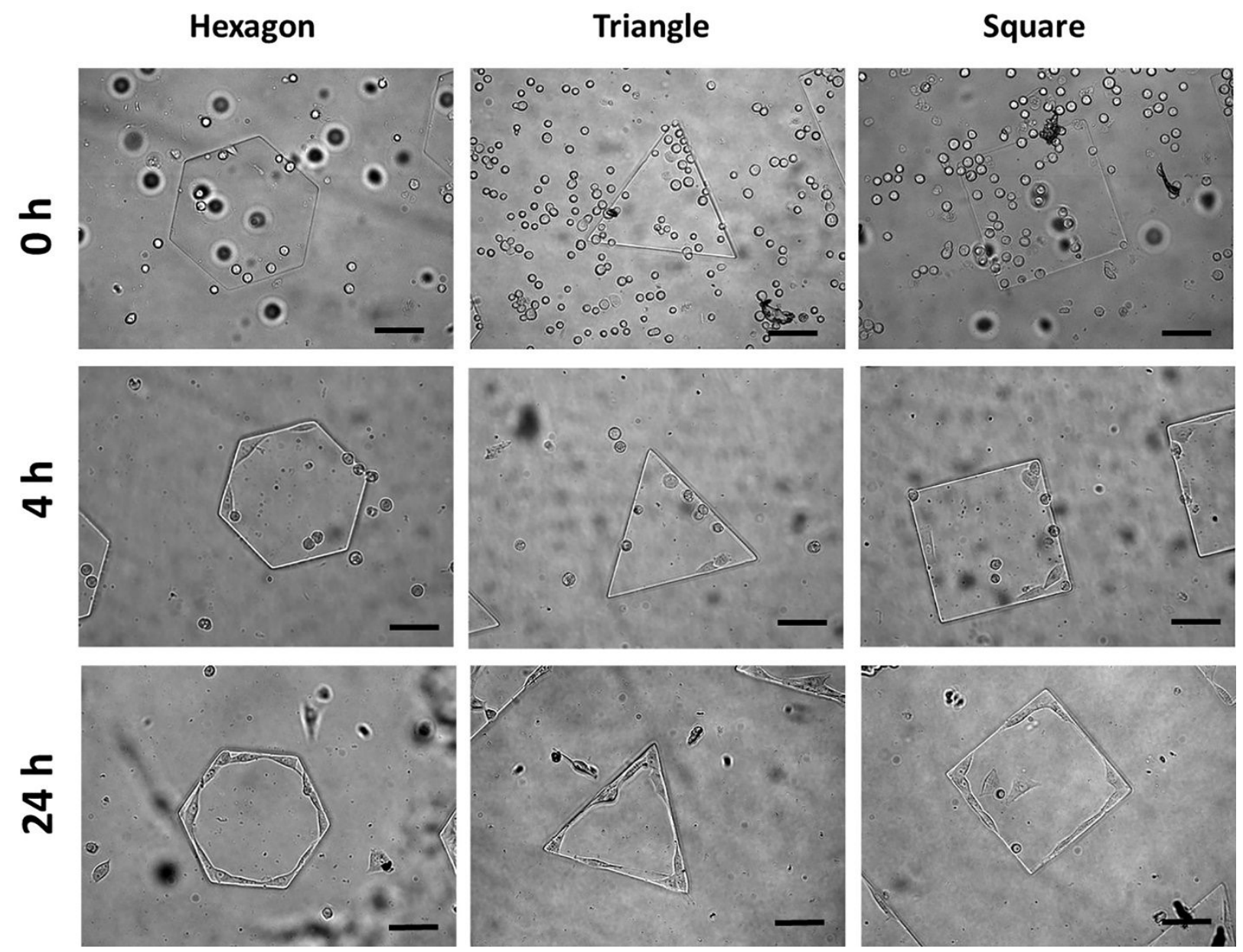

Figure S4. Bright field images showing round cells at early time points of cell seeding. At $4 \mathrm{~h}$ the cells migrated to the edges. (Scale=100 $\mu \mathrm{m}$ ). 
With Gelatin

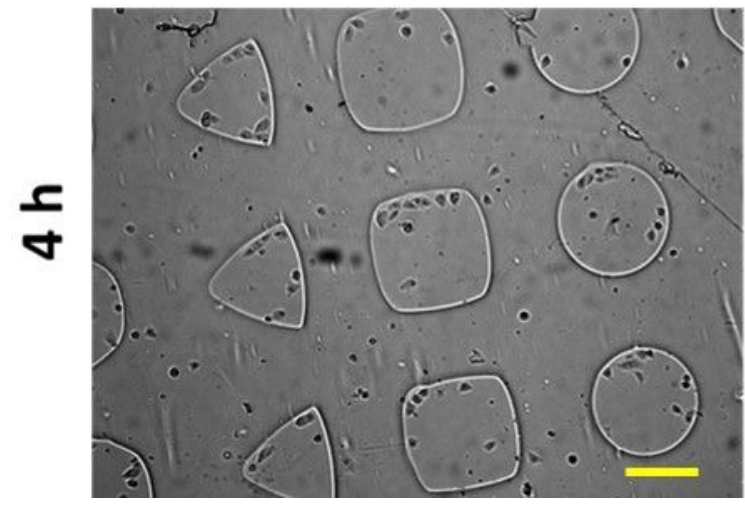

Without Gelatin

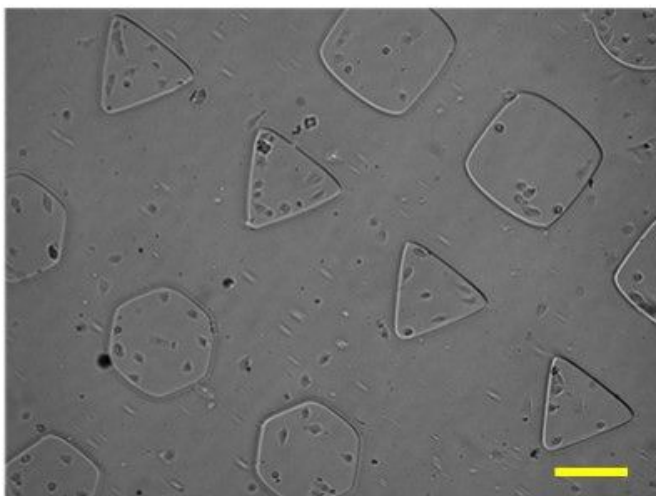

Figure S5. Bright Field images of patterns showing that there was no change in cell behavior after functionalization with a cell adherent protein. (Scale $=200 \mu \mathrm{m})$

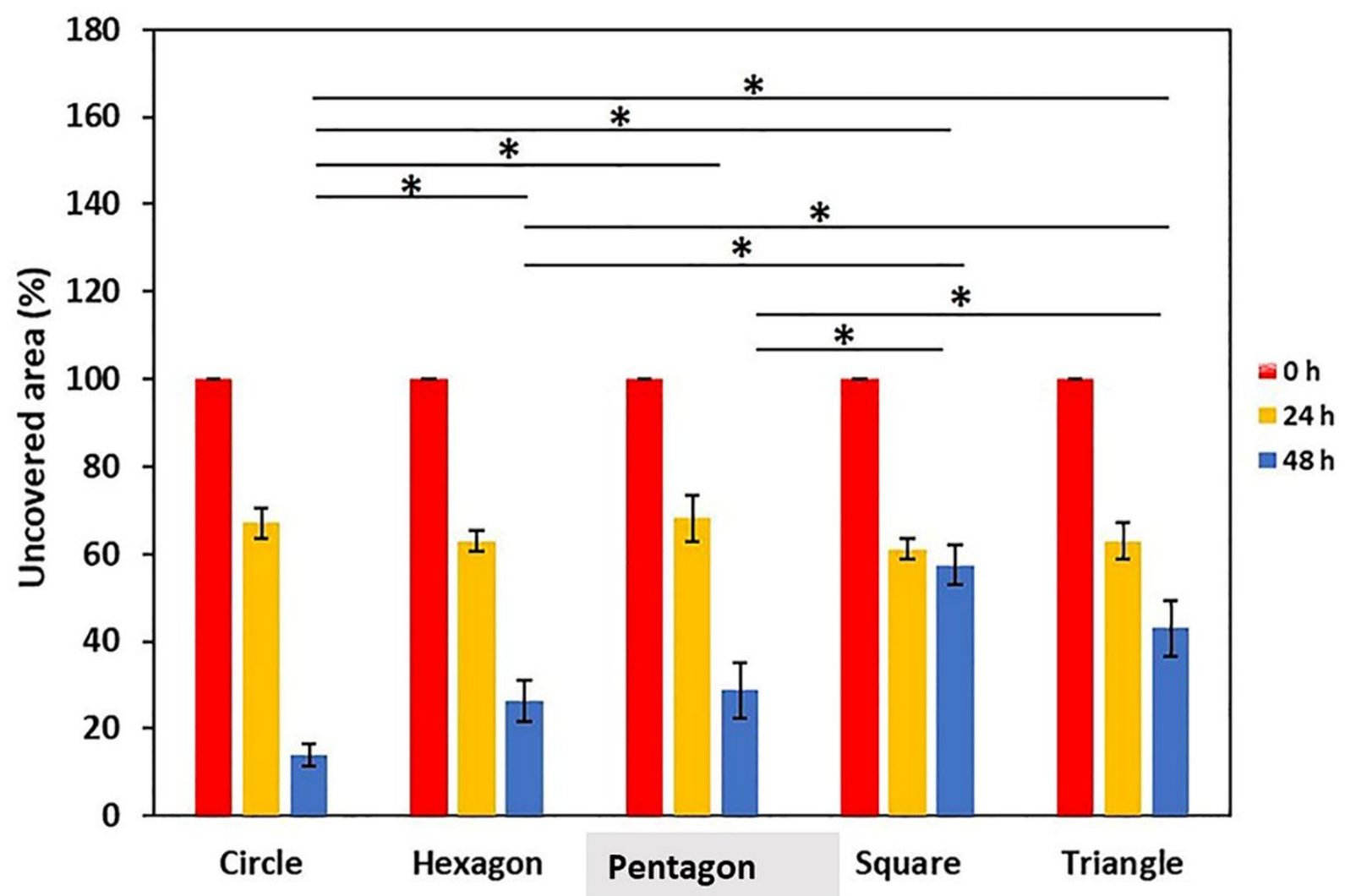

Figure S6. . Quantification of cell migration process for each geometry with respect to time by calculating the \% uncovered area using Image J software. The quantification was done for the image obtained from Figure $2(* \mathrm{p}<0.05)$ 

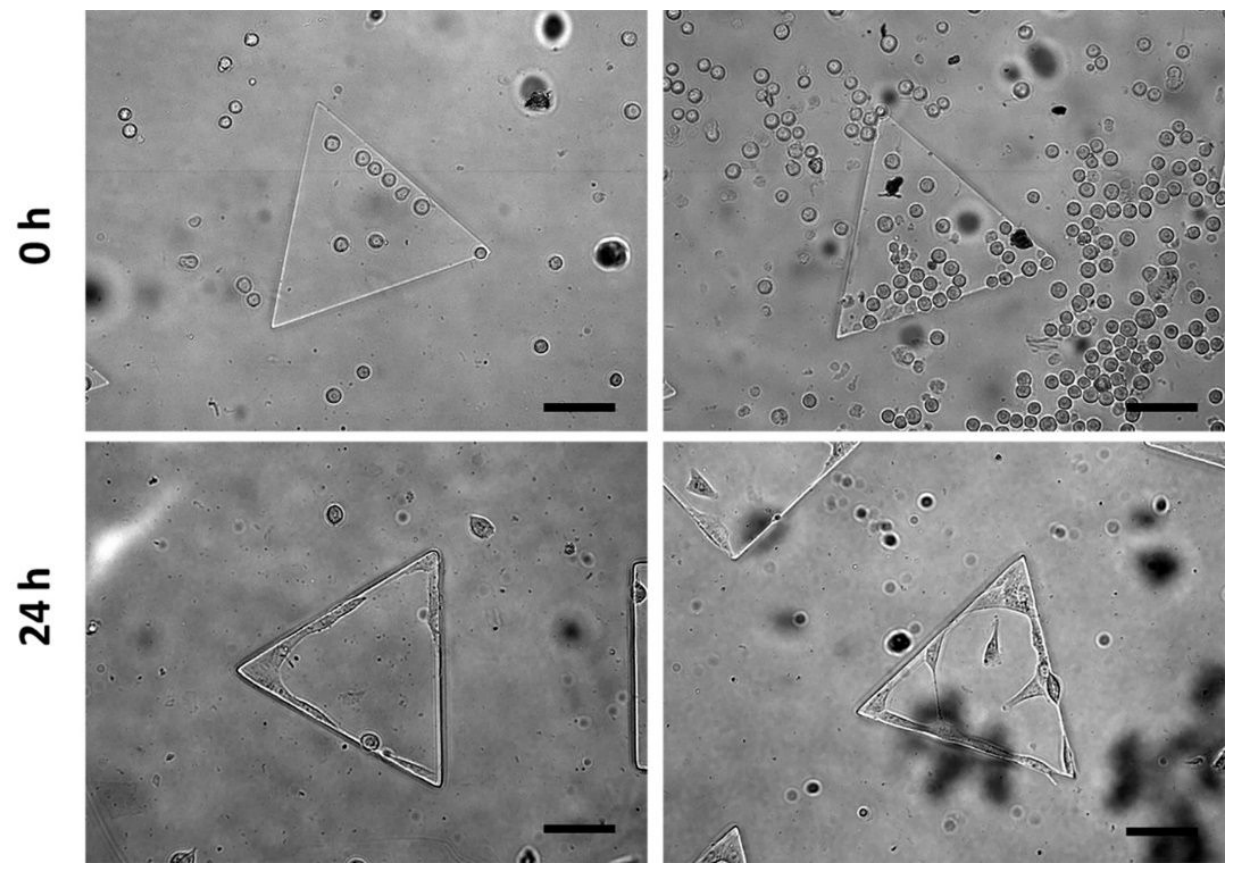

Figure S7. Bright field images showing the cell migration process is cell density independent (Cells were seeded at a density of 10000 cells/ $\mathrm{ml}$ and 30000 cells $/ \mathrm{ml}$ respectively and was imaged after $24 \mathrm{~h}$ of culture) (scale $=100 \mu \mathrm{m})$.

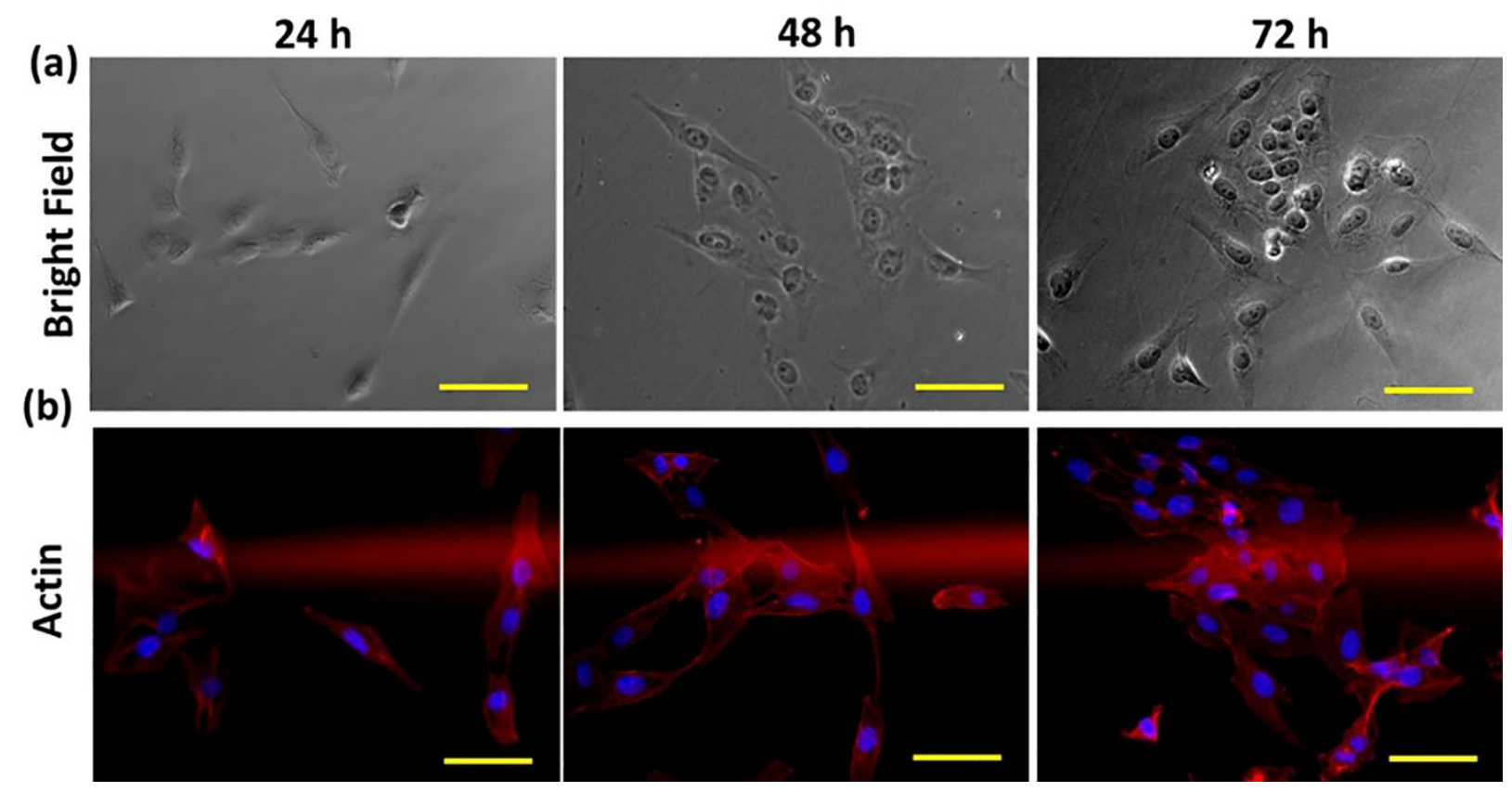


Fig S8. Fluorescence microscopic images of the cells cultured in a tissue culture plate at different time points. The images clearly shows that the cells were randomly aligned even after $72 \mathrm{~h}$ of culture.

(Scale $=100 \mu \mathrm{m}$ )

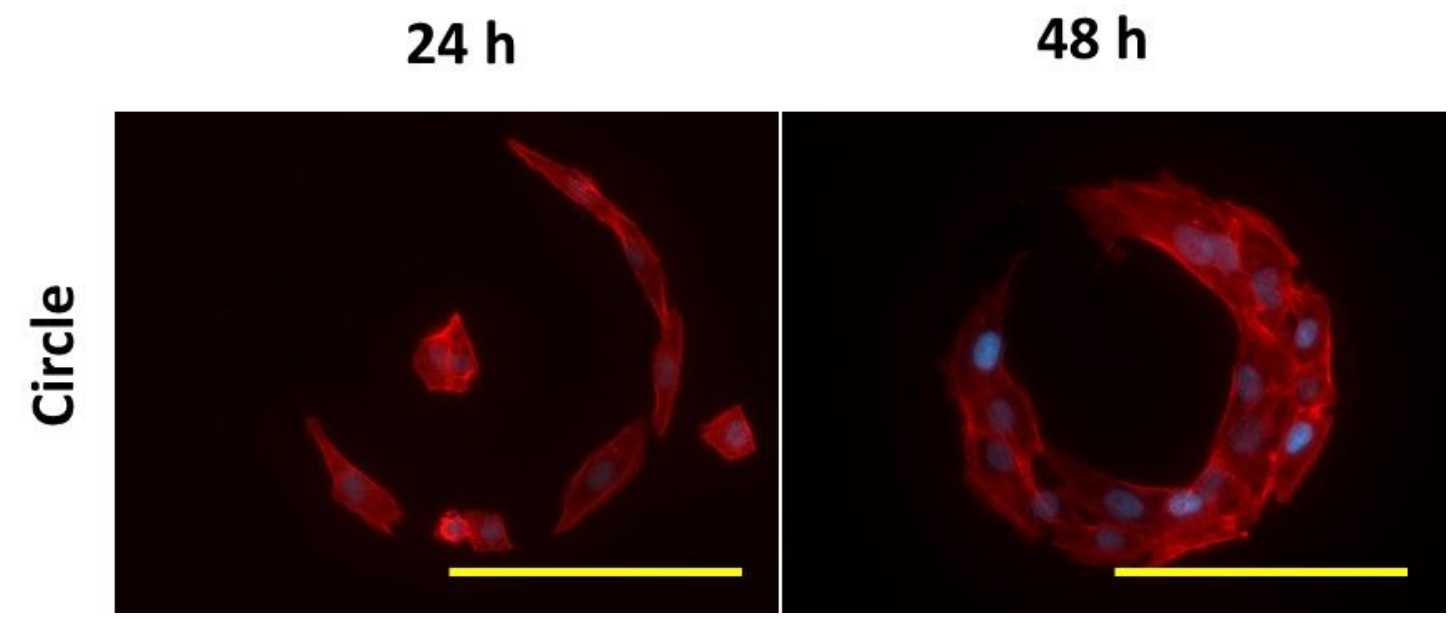

FigureS9. Fluorescence microscopic images (nuclei stained in blue with DAPI, cell cytoskeleton is stained red with Alexa Flour Phalloidin) showing there was no difference in the cells aligned at the corners. (Scale $=200 \mu \mathrm{m}$ ).

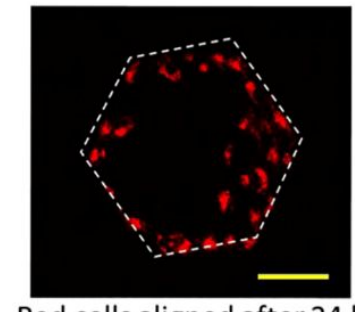

Red cells aligned after $24 \mathrm{~h}$

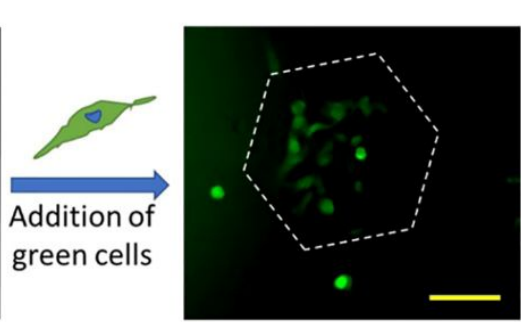

Green stained cells

Cell alignment after $48 \mathrm{~h}$

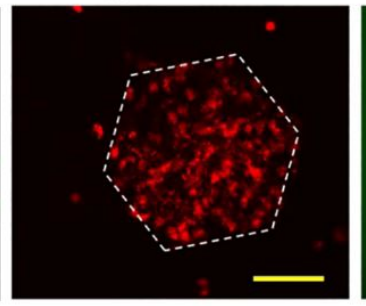

Red stained cells

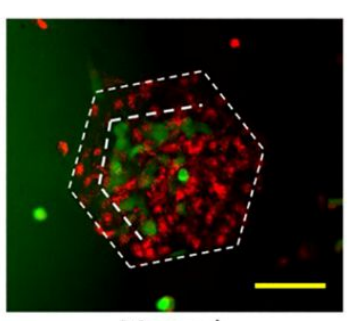

Merged

FigureS10. Fluorescence microscopic images of patterned cells after copattern of red ( $15000 \mathrm{cells} / \mathrm{ml})$ and green stained cells $(15000$ cells $/ \mathrm{ml})($ scale $=100 \mu \mathrm{m})$. 